\title{
MARCAS MEMORABLES EN LOS RELATOS COLLAS DE ATACAMA
}

\author{
MEMORABLE MILESTONES IN THE STORIES OF THE COLLA \\ FROM ATACAMA
}

\author{
Raúl Molina Otárola ${ }^{1,2}$
}

\begin{abstract}
Este escrito intenta iluminar la presencia de los collas en el desierto de Atacama, considerándolos sujetos sociales e históricos que habitan un espacio muchas veces estimado despoblado. Propone reconstruir la vida social a partir de sus relatos y detenerse en los eventos cualitativos que aparecen en estos cuerpos narrativos, dando cuenta de cambios en las condiciones de existencia en estos territorios habitados y en su mayoría desconocidos. Los eventos cualitativos y transformadores de la vida social son considerados marcas memorables, pues discursivamente deslindan un antes y un después en la cotidianeidad del devenir de los collas. Constituyen episodios con densidad de contenidos, significados e implicancias, que los convierte en eslabones para historizar la trayectoria de los collas en el desierto y la cordillera de Atacama. Para ejemplificar estas marcas memorables se analizan dos eventos de gran relevancia para estas comunidades: la última fiesta a la Pachamama en Pedernales, celebrada en 1953, y la sequía en la Quebrada de Paipote, ocurrida en 1958.
\end{abstract}

Palabras claves: Collas, marcas memoriales, reconstrucción histórica y desierto.

This paper attempts to highlight the presence of the Colla people in the Atacama Desert as social and historical subjects, who inhabit a space often regarded as a deserted area. It proposes an analysis of stories and memories in order to reconstruct the social life of the Collas. It will focus on the qualitative events of these narratives, which account for the changes in the living conditions in these inhabited and mostly unknown territories. These events are considered as memorable milestones, because in these narratives/stories they act as landmarks that set the limits between "before" and "after" in the social and economic everyday life. At the same time, they constitute episodes in which the density of contents, meanings and implications, creates links that allow historicizing the Colla's presence in the Atacama Desert. In order to exemplify these memorable milestones, we will analyze two events of great importance for these communities: the last ritual festival to the Pachamama in Pedernales, held in 1953, and a drought in Paipote Gorge, which took place in 1958.

Key words: Collas, memorable milestones, historical reconstruction, desert.

\section{El Desierto: un Espacio "Sin Memoria"}

El desierto de Atacama fue considerado un espacio despoblado en períodos coloniales (Bibar 2001) y un lugar ignoto y sin gente durante la república (Vicuña 1995), en suma un territorio sin memoria (Molina 2010a). Desconocido parcialmente en su geografía, fue destacado en los siglos XIX y XX por sus enclaves mineros y salitreros, pero continuó mayormente ignorado al tratarse de ocupaciones indígenas. A diferencia de los changos de la costa y de los atacameños de los ayllus y oasis del Salar de Atacama, de los que existen antecedentes históricos, los collas permanecieron ignorados, pese a que su presencia en el desierto y cordilleras de la provincias de Chañaral y Copiapó se remonta a fines del siglo XIX (Escolar 2005; Molina 2010b,
2012). A principios de la década de 1990, su vida social y económica estaba escasamente registrada. Un breve artículo tituló metafóricamente: "Los Collas: Fantasmas en la Cordillera", dado que aparecen y desaparecen en las quebradas del desierto de Atacama (Castillo et al. 1993).

Los collas en las cordilleras y desierto sur de Atacama permanecieron en el anonimato para los gobiernos y la sociedad chilena, no así para la sociedad local. Un extrabajador del mineral de cobre de Potrerillos recuerda que en la década de 1940: “...llegaban unos collas,... bajaban a vender quesos, y las collas grandecitas, usted las veía en el cerro y al rato ya estaban allá (lejos), ya se perdían por unas lomas" (N. Huanchicay, Huasco Alto, noviembre 2004, Molina 2012). Autores en la década de 1970 caracterizan a los collas como viajeros del desierto

1 Centro de Investigaciones del Hombre en el Desierto (CIHDE), Arica, Chile. raul.otarola@gmail.com

2 Universidad de Tarapacá, 18 de Septiembre 2222, Arica, Chile. 
y de la puna (Bahamondes 1978). Arqueólogos los observan en su actividad trashumante, ocupando tambos del camino del inca (Irribarren y Bergolhtz 1973) o recorriendo las inmediaciones del mineral de El Salvador y el Salar de Pedernales (Iribarren 1976). Rojas (1976) tiene el mérito de efectuar el primer reporte etnográfico en las aguadas de Castilla y San Juan, y los define como pastores de cabras, burros y ovejas, y asalariados en oficios vinculados a la minería.

A partir de la década de 1990 se inicia un acercamiento más sistemático a los collas. Se establece que las primeras familias llegan a fines del siglo XIX a la zona de Potrerillos y Quebrada de Paipote. Provienen de los valles de Fiambala y de diversos lugares de la puna de Atacama, en el noroeste argentino (NOA) (Garrido 2000; Molina 2004). Otras familias arriban desde el Salar de Atacama o son pastores locales que formaron parte del antiguo pueblo de indios de San Fernando de Copiapó. También se incorpora población mestiza proveniente del sur de Copiapó (Molina 2012). Los estudios aclaran que el etnónimo colla es una generalización que se hace para los indígenas de la Puna de Atacama durante el período que esta perteneció a la República de Bolivia, y que se siguió utilizando hasta la actualidad. Precaven que los colla de Atacama no tienen relación directa con los reinos Kollas del lago Titicaca, que muchas veces se presta a confusión, sino más bien poseen lazos de parentesco con los atacameños y otras poblaciones indígenas, y su constitución social es producto de procesos de movilidad colonial y republicana que ocurren en el desierto y la puna de Atacama (Manríquez y Martínez 1995; Martínez 1998; Molina 2010b). Los estudios etnográficos se ocupan de sus actividades económicas, el uso de extensos territorios y describen algunos asentamientos (Cervellino y Zepeda 1994; Cobs 2000; Garrido 2000; Molina 2008; Ponce 1998). Tratan además de sus linajes y parentescos, de su relación con el medioambiente y el conocimiento de la naturaleza, de sus rituales y cosmovisión (Cervellino 1993). Algunos abordan aspectos de su identidad en formación (Castillo et al. 1993), otros de modo somero describen el persistente proceso de asalarización y algunos se aproximan a la migración campo-ciudad ocurrida a partir de la década de 1970, que explica por qué la gran mayoría de quienes hoy se autorreconocen collas vivan en zonas urbanas. Otros estudios destacan el reconocimiento legal como etnia y la formación de comunidades indígenas a partir de 1995 (Molina 2004; Molina et al. 2000). Estos antecedentes muestran la complejidad que supone comprender la diversidad colla, tanto étnica, social y territorial, y los desafíos que involucra intentar reconstruir su trayectoria en el desierto y la cordillera de Atacama.

Los trabajos etnográficos citados se basan especialmente en entrevistas a collas de Potrerillos y Quebrada Paipote, testimonios que no han sido recogidos en su integridad y/o analizados como textos en su contexto, es decir, como descripción densa (Geertz 1973). Este artículo se basa en relatos collas recogidos entre los años 1996 y 2005. Busco en ellos marcas memorables, inflexiones en la vida cotidiana que han transfigurado su devenir y develan la complejidad de la trayectoria social de los collas en Atacama.

\section{Memoria y Marcas Memorables}

Los relatos collas responden a ciertas preguntas temáticas y se expresan en narrativas que ordenan el pasado anidado en la memoria (Candeau 2006). Comprenden sucesos relacionados con sus prácticas culturales, la vida cotidiana, el poblamiento, las relaciones interétnicas y el manejo del medio geográfico. Son testimonios cargados de sentidos, que Sitton et al. (2005) los considera historias que ya están entre ellos. Estos relatos contienen hechos que han impactado su vida social y por su relevancia no forman parte del olvido (Candeau 2006; Ricoeur 2003). Se trata de marcas memorables surgidas de cambios drásticos, que no son parte de la perspectiva sicológica del trauma social (Ortega 2011; Wendy 2000), sino del sentido dialéctico de la continuidad y la transformación histórica (Ricoeur 2003).

Las marcas memorables circunscriben en el tiempo y en el espacio acontecimientos que discursivamente deslindan y unen dos tiempos narrativos, el antes y el después, y en algunos casos señalan las causas y/o efectos de los cambios ocurridos. La identificación de marcas memorables posibilita la comprensión de cambios históricos acontecidos en la vida local y cotidiana de los collas, y destaca una dimensión social e histórica del desierto de Atacama.

Las marcas memorables, como piezas de un rompecabezas, son parte de la historicidad colla y pueden llegar a nutrir su reciente proceso de etnicidad (Giddens 2000) que demanda reconocimiento social 
y derechos indígenas, estos últimos sobre tierras y aguas ocupadas en sus alicaídas economías ganaderas. A la vez, las marcas memorables pueden ayudar a sistematizar la memoria colectiva colla, dificultada por la residencia mayoritaria de sus miembros en zonas urbanas, los que carecen mayoritariamente de un discurso umbilical que los una a la vida de campo, el espacio del desierto y la cordillera.

\section{Ciclo Anual y Marca Memorables}

La memoria de las prácticas y de los acontecimientos collas expresada como relato puede ordenarse en el ciclo anual como tiempo-calendario (Le Goff 1982) o bien como eventos excepcionales, marcas memorables que han transformado la realidad social. Entre los pastores collas tradicionales, el tiempo-calendario anual, al igual que en otras zonas andinas, se constituye a partir de las actividades económicas, productivas, rituales, ceremoniales y sociales, ordenadas diacrónicamente en la sucesión de días y meses del calendario occidental (Gavilán y Carrasco 2009).

Entre los pastores collas tradicionales y subsistentes de la cordillera de Copiapó y Chañaral, el ciclo anual está bien expresado en la trashumancia ganadera entre invernadas y veranadas, y en el uso de pisos ecológicos del desierto y la puna (Molina et al. 2000). Este ciclo incluyó en décadas anteriores, labores y tareas relacionadas con la ganadería, la agricultura, la caza, la recolección, la minería y las actividades de intercambios y comercio. Existió también un almanaque ritual de conmemoración a los santos patronos, realización de fiestas a la Pachamama o Santa Madre Tierra, y celebraciones asociadas a la reproducción del ganado, que se extinguieron en décadas pasadas (Cervellino 1993). Estos acontecimientos ocuparon un orden y lugar en el calendario colla, como ocurre hasta el presente en otras zonas andinas (Grebe 1981; Martínez 2001; Van der Berg 1989; Van Kessel 1992). Actualmente entre los collas, algunas celebraciones han sido recreadas y otros ritos, celebraciones y fiestas son de reciente aparición.

Al interior de estos calendarios anuales es posible encontrar marcas memorables que contienen información de sucesos transfiguradores del devenir histórico, que evidencian un cambio cualitativo y/o cuantitativo en la cotidianidad, el poblamiento y el modo de habitar el desierto y la cordillera. Narran el tránsito de una normalidad conocida a una situación alterada que crea nuevas condiciones de existencia social. Son un tipo de discurso nodal de hechos sociales o naturales que unen los cambios de la historicidad colla. Ellos dan cuenta de las causas y/o de los efectos de fenómenos sociales o naturales, como las sequías, que afectan la ganadería, la trashumancia e impactan en la reproducción social como pastores. Las marcas memorables pueden ser descritas con cierto detalle y revivirse en la memoria individual como tiempo real, e incluso convertirse en relatos colectivos, cuando la información es consensuada por el grupo social (Rosa et al. 2000).

Al detenerse en estos acontecimientos, es posible por medio del análisis del texto y del contexto del relato, ingresar a narraciones de una alta densidad descriptiva (Geertz 1973) que develan severos cambios en la vida social. Son las marcas memorables que ayudan a construir su memoria histórico-social (Halbwachs 2002), mediante sucesos relacionados con conflictos sociales, económicos, políticos o medioambientales. Estos pueden ser interrogados acerca de sus sentidos y significados (sensu Gadamer 2001), teniendo presente el lugar de la geografía donde transcurren los hechos vividos y recordados (Nora 2009; Schutz 1974). Las marcas memorables puestas en tensión dialéctica expresarán las fuerzas en pugna y los cambios cualitativos y/o cuantitativos que se guardan en la memoria. Al ser ordenadas en el tiempo y en el espacio configuran un complejo mosaico de relatos nodales del pasado y el presente que articulan la dinámica histórica de los collas de Atacama. Como ejemplo analizo dos relatos etnográficos, marcas memorables, ocurridos en la década de 1950 en la zona de Potrerillos y en la Quebrada de Paipote. Ambos ayudan a la comprensión de la situación actual de los collas.

\section{La Última Fiesta a la Pachamama en Pedernales}

Pedernales es un territorio ubicado en el altiplano de Copiapó y emplazado a $3.400 \mathrm{msm}$. Se compone de un salar de gran extensión que está coronado al norte por el volcán Doña Inés, y en su margen sur existen extensas pampas y pequeñas serranías con quebradas, vertientes y pastos, lugar especial para la crianza de animales. Por estas características fue asentamiento elegido por los collas a fines del siglo XIX y principios del siglo XX. Su localización 
territorial era inmejorable para el abastecimiento de productos artesanales y ganaderos a centros poblados y explotaciones mineras del desierto. Así, desde la segunda década del siglo XX los collas desde Pedernales articularon su producción al abastecimiento del mineral de cobre de Potrerillos.

Pedernales estaba formado por varias viviendas separadas entre sí, y fue centro de las estancias ganaderas llamadas: Estaquitas, Cerro Blanco, Los Piques, Peña Blanca, Pajaritos, Cencerrito, Barros Negros y La Ola. “...había re mucha gente aquí para los campos de La Ola y Pedernales, El Tambo (Barros Negros), y con harta crianza de animales" (Esteban Ramos, Montandón, junio 2005).

Las personas o familias collas de Pedernales provenían mayoritariamente de los valles circumpuneños de Fiambala y de Santa María, y de localidades de la Puna de Atacama, como Antofagasta de la Sierra y Pastos Grandes (Cervellino y Cepeda 1994; Garrido 2000; Molina 2004). En Pedernales la actividad productiva estaba formada por la ganadería de caprinos, ovinos, llamos y burros, la caza de guanacos, vicuñas, zorros y chinchillas, y la recolección de leña y confección de carbón. Se realizaban intercambios y compra de productos con el mineral de Potrerillos (tejidos, quesos y carne intercambiados por azúcar, harina, grasa, conservas, herramientas y artículos de tocador y limpieza), y se comerciaban animales, pieles de camélidos, zorros y chinchillas, y hojas de coca con los pueblos del Salar de Atacama. Mantuvieron un sostenido cambalache o trueque con el valle de Fiambala, para obtener tejidos de lana, mulas, hojas de coca, alcohol y frutas (uva, pasas y paltas). Con otros poblados collas cercanos, como los de Doña Inés, Aguadas San Juan, Aguada Castilla y el Agua Dulce, mantuvieron estrechos lazos económicos, sociales y rituales (Molina 2010b).

El calendario anual estaba formado por las actividades productivas, la trashumancia ganadera, las fechas de intercambio y las fiestas colectivas. En la estancia de Cerro Blanco, Quebrada de Pedernales, se realizaban fiestas religiosas a los santos patronos, se celebraban las Pascuas y Años Nuevos, se efectuaban las Challas, la Señalada, la Marcada y el Floreo de animales. En Cerro Blanco se reunía la mayoría de la gente de las estancias de Pircas Negras, Cencerrito, Los Piques, Salitral para celebrar las fiestas que duraban dos o tres días, donde se domaban animales, se hacían las fiestas de primicias y se entregaba la ofrenda de animales y frutos a la Pachamama (Salomón Gerónimo de El Agua Dulce, noviembre 1997, Molina 2004, 217).

La fiesta a la Pachamama era un hito relevante en la vida social y productiva de los collas. Don Jesús Albino Escalante, relata:

En la Quebrada de Pedernales la hacíamos todos los años. Se predestina el día de la Pachamama Santa Tierra, se convidaba gente, se hacía una minga, y el dueño de casa destinaba dos animales para la fiesta. La fiesta del día de los vivos se hacía un día antes y al día siguiente la fiesta a la Pachamama. Todo lo que quedo, la carne y otros alimentos, se llevaban para ofrendarlos a la Pachamama. Se buscaba donde se juntan dos o tres caminos troperos y se hacían un hoyo grande, se bailaba se pedía para un año bueno, que nevé, que los animales cundan (Jesús Escalante (77) El Asiento, mayo 2005. Diario de campo).

Esta fiesta tradicional, inserta en el calendario anual, era un evento importante de la cotidianidad material y espiritual colla. Ella se constituyó en una marca memorable, en un hito simbólico, en la conciencia comunitaria de los collas de Pedernales.

En la última fiesta realizada a la Pachamama Santa Tierra, cuando terminábamos los ganados, cuando se terminaron las ovejas, las cabras, participaron Tomasa Jerónimo, Basilia, María, Zulema y Román Escalante. Se agregó la 'finá' (finada) Cristina Jerónimo mamá de la señora Tomasa casada con Juan Marcial. Participó también Pedro Jerónimo que murió en el Jardín, Gregorio Jerónimo. Esta última celebración fue realizada cuando dimos por caducada la crianza por los años malos, eso fue entre 1952 y 1953. A partir de ese momento, la gente colla comenzó a buscar trabajo en Potrerillos. Y a nosotros nos tocó la contaminación cuando los gringos echaron a andar una planta de ácido sulfúrico durante 10 años, y la chimenea comenzó a botar humo toxico y los animales se volvían medios locos. Eso comenzó en el año 1948, lo que ayudó a terminar con los animales. El humo de la chimenea, era como hollín, se pegaba en los pastos y los animales comían y se volvían locos, se les 
podrían las patitas y se le hacían heridas, igual como una enfermedad que ahora tienen los guanacos de los cerros. Cuando se dieron cuenta de lo que estaba produciendo la planta de arsénico, la pararon, pero eso fue como en el año 1957.

En esos años algunos se fueron al trabajo a Potrerillos y otros siguieron en el campo. Mi madrina Damiana siguió con los animales. En esos años hubo gente que se volvió a la Argentina, como los Bustamante (Jesús Escalante (77) El Asiento, mayo 2005. Diario de campo).

La última fiesta a la Pachamama en Pedernales es un hito de término y transformación. Para muchos collas ocurrió el fin de la ganadería, el abandono del poblado, la migración y/o dispersión de la población, la asalarización, el cambio de residencia, el término de la vida ritual y de las ceremonias colectivas. Es un cambio drástico inducido por los "años malos" y la "contaminación". Me detengo a analizar la densidad de cada frase significativa de este relato.

La aseveración "terminábamos los ganados" connota la decisión de acabar con la actividad pastoril que afecta a una o varias familias, aunque no a todas. Ello ocurre en dos coordenadas, la del tiempo (años 1952-1953) y la del espacio (Pedernales). El término de la ganadería y el abandono de Pedernales por la mayor parte de la población implica también el fin de las fiestas, ritos y celebraciones colectivas. Estas quedaran recluidas a celebraciones más íntimas o familiares.

El término de la actividad ganadera se debe a la presencia de "años malos", de sequía, a la falta de lluvia y nieve, y escasez de pastos para alimentar el ganado. La sequía está antecedida en el relato por un evento de origen humano, que potencia sus efectos nocivos. Se trata de la contaminación que desde 1948 originan los hornos de la fundición de Potrerillos. A la sequía se suma el "humo tóxico", "el humo de la chimenea" causante de los estragos en los campos de pastoreo que han sido contaminados con el "hollín", que "volvían locos" a los animales, "pudrían las patitas" y les "hacían heridas". La contaminación y la sequía afecta la principal actividad económica de los collas: la ganadería, y provoca el abandono del lugar.

El relato de la última fiesta a la Pachamama es una marca memorable. Evoca un hito simbólico al interior del grupo social que participó de este acontecimiento, que traído al presente, actúa como explicación de la conclusión de un proceso que comenzó a ocurrir años antes. Este evento en la memoria de los descendientes de los collas de Pedernales, es rememorado, pero solo han trascendido los efectos provocados por la contaminación de los pastos por la fundación de Potrerillos:

El pastoreo de acá de la cordillera se abandonó por eso, todo lo que es Cordillera del Bravo hasta La Ola, esta cordillera un tiempo estuvo contaminada. Tan contaminada que los animales de trabajo se tenían que reponerse todos los años, si usted compraba 10 burros para trabajar en este verano a vuelta de verano estos animales no estaban, porque con la contaminación del arsénico los animales se morían, así que había que reponer año a año... Ese fue uno de los motivos de que los pastoreos quedaran abandonados (Zoilo Jerónimo, Potrerillos, noviembre 1996)

Esta marca memorable es una fractura en la vida social, una alteración de las condiciones de vida y existencia, un acontecimiento relevante en el discurso histórico, que cierra un período de vida en comunidad, terminando con la ganadería masiva y desapareciendo de Pedernales una de las celebraciones comunitarias y rituales más relevantes para los collas; la fiesta a la Pachamama.

La última fiesta a la Pachamama es un relato clave para comprender la situación contemporánea de los collas, algunos ahora dispersos en la zona de Potrerillos o radicados en gran parte en pueblos y ciudades. Ciertos pobladores, descendientes de las familias Taquía, Salva, Jerónimo, Morales, Marcial y Reinoso, aun permanecen de un modo precario desarrollando la trashumancia ganadera de cabras y burros, incluyendo como lugar de paso la zona de Pedernales.

Después de la última fiesta a la Pachamama en Pedernales, el tiempo transcurrido no puede entenderse como una linealidad histórica y sin cambios en la vida social. La zona de Potrerillos y Pedernales continuó siendo afectada por sucesivas sequías y nuevos acontecimientos con repercusiones socioproductivas, culturales y políticas, hechos que podrían ser considerados marcas memorables, eslabones del devenir histórico de los collas en la zona de Potrerillos (Figura 1). 


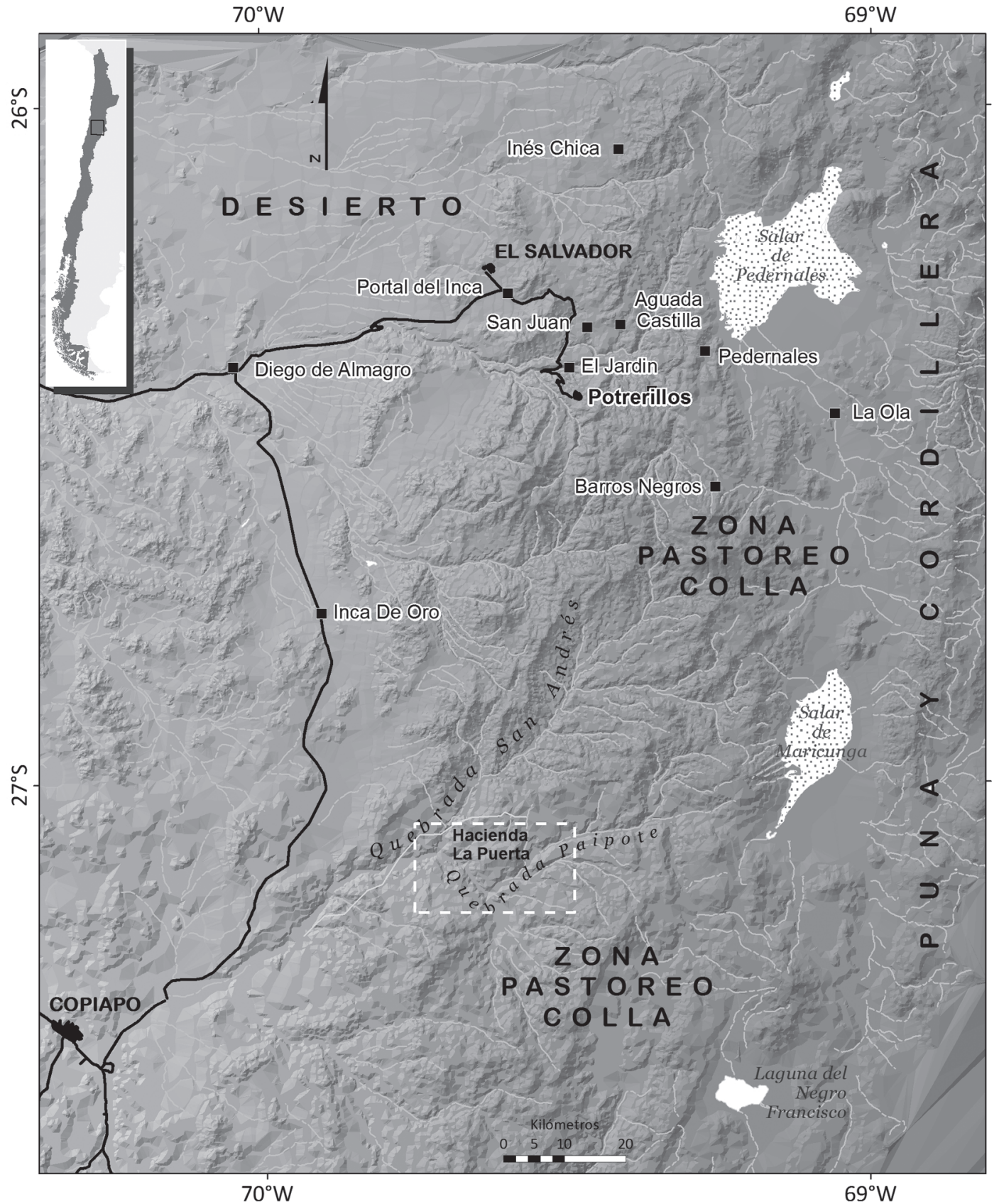

Figura 1. Mapa de la zona de Pedernales y Quebrada Paipote. Zone map: Pedernales and Paipote Gorge.

\section{La Sequía de 1958 en la Quebrada de Paipote}

Este segundo relato refiere a la sección de la Quebrada Paipote ubicada en la precordillera de Copiapó, a partir del lugar llamado La Puerta, donde la quebrada se estrecha y es flanqueada por cerros secos y sin vegetación. Allí aún es posible apreciar en el fondo del valle algunos potreros de alfalfa y siguiendo la quebrada arriba aparecen las vegas Escorial, Redonda, Dadinal y Cebollar, que presentan pequeñas formaciones de vegetación, con brea, dadín, tamarugos y algarrobos. Subiendo se alcanza un lugar llamado El Bolo y las vegas El Obispo, Pastos Grandes, Pastillos, Tapia y Las 
Juntas. Estos terrenos pertenecieron a la Hacienda La Puerta, antiguamente denominada Potreros de la Iglesia (Molina 2004). En El Bolo vivió don Paulino Bordones, con quien conversé en varias ocasiones entre 1996 y 1998. En sus relatos, una de las marcas memorables era la sequía ocurrida a fines de la década del cincuenta. Este era a su parecer el hito que provocó cambios en la vegetación, en el poblamiento y en las relaciones sociales a nivel local. El evento ambiental generó una inflexión histórica, un antes y un después en la vida social de la Quebrada de Paipote. La sequía transformó el poblamiento y el ordenamiento productivo de la quebrada.

Aquí desde el 58, más o menos, comenzó a mermar el agua. Para el año treinta (1930) usted venía y estos cerros estaban cubiertos de nieve, no podía entrar a ninguna parte acá, quebradas parejas de nieve. En todos estos cerros se alcanzaba la nieve de un año al otro; corrían las aguas de todas partes, donde iba había agua, los campos daban gusto, todas estas quebradas, para el lado de Inca de Oro era puro pasto (Paulino Bordones, El Bolo, noviembre 1996).

El relato resalta la abundancia de aguas, nieve y pastos de un tiempo pasado. Expresiones como "quebradas parejas de nieve", "corrían las aguas de todas partes" y "era puro pasto" son elocuentes, y evocan un paisaje difícil de encontrar en la actualidad. Las expresiones de abundancia contrastan con la sequedad de los cerros y de la quebrada, con la escasez de agua y la reducida agricultura de potreros de alfalfa que se aprecia en el presente. El relato destaca el año 1958 como marcador temporal del inicio de la sequía y de los cambios ambientales, cuando "comenzó a mermar el agua" hasta hacerla insuficiente para regar los cultivos agrícolas, generando la actual situación ambiental, caracterizada por la estrecha disponibilidad de aguas que brotan de pequeñas y distanciadas vertientes.

¿Cuáles fueron los efectos sociales de la sequía? ¿Por qué se puede considerar una marca memorable? Para responder es necesario señalar que las tierras de la Quebrada de Paipote eran propiedad de la Sucesión Cousiño, que en la década de 1950 las arrendaba para agricultura. Los arrendatarios a su vez establecieron relaciones sociales de inquilinaje, mediería y tratos libres con los trabajadores. Pero restringieron la ocupación de estos terrenos a los collas.

Don Justo Juárez era el que tenía estas tierras..., no dejaba que trabajara nadie, y todo lo que se sembraba libre, él lo quitaba o tenía que darle las partes por iguales...". "Aquí se trabajaban los potreros, pero nadie podía tener sus animales aquí, porque (los collas) eran crianceros, tenían que tenerlos en la cordillera (Paulino Bordones, El Bolo, noviembre 1996).

El relato describe las relaciones sociales previas a la ocurrencia del evento de la sequía, cuando existía abundancia de aguas, nieves y pastos. El arrendatario de la hacienda "no dejaba que trabajara nadie", por tanto, un ocupante colla no podía hacer uso libre de las tierras, estaba impedido de efectuar cultivos, so pena de perder la siembra, pues “...todo lo que se sembraba, él lo quitaba”. La única relación productiva aceptada era la mediería, "tenía que darle las partes por iguales". Tampoco se toleraba la tenencia y el pastoreo de animales en los terrenos de fondo de valle o cercanos al área de cultivo de la hacienda, "tenían que tenerlos en la cordillera", es decir, en sectores altos de las quebradas y en los campos de pastoreo de la puna de Copiapó. Quienes no aceptaban este régimen de explotación debían abandonar el lugar.

El relato nos habla de espacios ecológicos asociados a dos tipos de ocupación; el de la hacienda y el de los pastores-agricultores, ocupantes libres. El espacio de la hacienda es el fondo de la quebrada que se extiende entre La Puerta y El Bolo, tramo que presenta disponibilidad de aguas y suelos planos, usados para la producción agrícola con fines comerciales. En cambio, las partes altas de la quebrada -las vegas Pastillo, Pastos Largos, Tapia y Las Juntas-, los cerros y altiplanicies son ocupados por los crianceros o pastores, algunos reconocidos como collas. Además, estos pobladores libres o enrolados en labores de la hacienda ocupan las serranías para el trabajo de leñaría y carboneo.

Se hacía leña de varilla, de caspiche y de pingo, y se llevaba a Copiapó. Al principio no se podía llevar leña a Copiapó, cuando estaba Justo Juárez, sólo se le podía vender a él y él pagaba con víveres, luego con el 
sindicato se pudo bajar la leña a Copiapó (Paulino Bordones, El Bolo, septiembre 1996).

Estas relaciones sociales y económicas se expresan también como espacios segregados; abajo el arrendatario y sus trabajadores agrícolas, arriba los collas con la ganadería y el carboneo. Ambos espacios se caracterizaron por sus vínculos de dependencia y conflicto, un ordenamiento social, productivo y ambiental que se extinguió con los estragos causados por la sequía, evento natural que actúa como marca memorable en algunos relatos collas.

Y de esa fecha (1958-1960), cuando se fueron los Papaprieto (que siguieron con el arrendamiento de las tierras a la muerte de Justo Juárez) se secó toda el agua. No había agua en ninguna parte, ni en la Hacienda. Fueron años malos. En Dadinal no había ni una gota. Aquí (en la quebrada) no vivía casi nadie en esos años, lo abandonó todo la gente y empezamos a subir más arriba; Las Juntas, Chinches, de Pastos Grandes, para arriba ya no mermó el agua. El trabajo en la Hacienda se terminó todo. Acá quedamos siempre nosotros (los Bordones Quiroga, los Quispes y los Araya). Nosotros éramos cuatro hermanos, cada uno con su 'ranchita', en Tapia, Pastillo y Pastos Grandes, esos eran los lugares donde había agua y donde se podía sembrar (Paulino Bordones, El Bolo, septiembre 1996).

Los efectos sociales y ambientales de la sequía provocan una inflexión en la vida cotidiana de la Quebrada de Paipote. Se acaba la sujeción a las relaciones hacendales y los conflictos con los arrendatarios particulares, cuyo hecho detonante, "se secó toda el agua", pone término a la actividad agrícola de la hacienda, "El trabajo en la Hacienda se terminó todo". En consecuencia se produce el abandono del lugar por parte de los arrendatarios, "se fueron los Papaprieto", ocluyéndose las relaciones de subordinación. Los collas quedan libres de la sujeción y permanecen en las abandonadas tierras de la Quebrada de Paipote.

El relato precisa geográficamente el repliegue a zonas interiores de la quebrada, donde había aguas, pues los campos de cultivos de la hacienda, "lo abandonó todo la gente y empezamos a subir más arriba". Esto implica que en la zona entre La Puerta hasta El Bolo cesó la agricultura y quedó abandonada, afectada por los estragos de la sequía y las restricciones de aguas. Los Bordones y Araya, autorreconocidos actualmente collas, debieron retroceder, "subir más arriba", hacia "los lugares donde había agua y donde se podía sembrar", es decir, en Pastillos, Pastos Grandes, Tapia y Las Juntas, pero posteriormente se vuelven a asentar en El Bolo, aprovechando un pequeño caudal de la aguada Obispito. Todos estos lugares corresponden a terrenos de fondo de quebrada, cuentan con unas pocas aguas y con un clima más frío, donde es posible el cultivo de la alfalfa en pequeñas superficies, que los collas usan en la actualidad para complementar la alimentación del ganado en invierno, cuando bajan de las veranadas.

El relato de la sequía de la década de 1950, como marca memorable, es una narración que ayuda a comprender la situación presente en la Quebrada de Paipote, pues las tierras no volvieron a ser utilizadas por empresarios agrícolas, conservando los collas la ocupación de estos territorios en su mayoría áridos: "Acá quedamos siempre nosotros" sentenciaba don Paulino Bordones.

\section{Otras Marcas Memorables en los Relatos Collas}

Las marcas memorables, "La última fiesta a la Pachamama en Pedernales" y "La sequía de 1958 en la Quebrada de Paipote", son nodos de sentido, eslabones que permiten historizar y comprender las alternativas de la presencia colla en el desierto y la cordillera de Atacama. En estos relatos aparece la sequía asociada al conflicto social con efectos diferenciados y desenlaces distintos. Mientras en Pedernales se produce el despoblamiento y la diáspora colla producto de la sequía y la contaminación minera, en la Quebrada de Paipote, la disminución dramática de las aguas para cultivos agrícolas, aleja a los hacendados y posibilita el asentamiento colla hasta nuestros días. Ambos relatos ocurren en tiempos y espacios geográficos distintos, lo cual otorga particularidad, diversidad y variabilidad a la historicidad colla, y nos propone la reconstrucción de una memoria social compleja, cuyas marcas memorables pueden dar sentido a ciertos lugares de memoria, como los propuestos por Nora (2009). 
En los relatos collas, el comportamiento del clima seguirá teniendo incidencia en los cambios drásticos de la vida social y económica, como la sequía de los años 1968 y 1969 que obligó a terminar con la ganadería a crianceros de Potrerillos (Zoilo y Salomón Gerónimo, comunicación personal 1997). Baste señalar que entre los años 1955 y 1977 precipitó un promedio de 7,85 mm anuales (Greim 2005). Estos eventos climáticos serán siempre potenciales marcas memorables, pues provocan estragos en las actividades ganaderas, generan migración y abandono del desierto y la cordillera.

Los conflictos económicos y territoriales también forman parte de las marcas memorables, como la pérdida de espacios de pastoreo y disputas por el agua con hacendados y empresas mineras. Por ejemplo, en la década de 1930, las aguadas de mejor calidad del cerro El Hueso y otras cercanas al mineral de Potrerillos son entubadas por la Andes Copper Mining, para faenas y abastecimiento minero. Esto provoca el abandono de esta zona de pastoreo. Otras pérdidas de tierras ocurren en desalojos con fuerza pública a pastores de Río Jorquera que ocupan la hacienda de los Prohens, hechos ocurridos en 1957 y 1959. Este conflicto termina en un nuevo deslinde, la Tranca de los Monos, que relega la ocupación colla a las tierras altas del valle, según relataban en 1997 Demetrio y Santos Cruz (Molina 2004). Esta marca memorable fue relevante en 1996 para demarcar el territorio de pastoreo (451.957 hectáreas) y obtener en propiedad la titulación de 5.707 hectáreas de fondo de valle en 1999 (Molina et al. 2000).

También las marcas memorables consideran conflictos políticos que ocurren a nivel nacional e internacional y que afectan la vida social de los collas. Por ejemplo, los efectos del golpe de Estado del 11 de septiembre de 1973 son mayúsculos entre los collas. Por bandos militares dictados en 1974 en Copiapó se prohíbe el ejercicio de la pequeña minería, la leñaría, la confección de carbón, y la crianza de ganado caprino (Farías 2005).

A nosotros nos cortaron los brazos como pequeños mineros cuando se ordenó que los que tenían un cartucho de dinamita eran guerrilleros, cuando entró Pinochet. Aquí había mucho pirquinero, en todas las familias, había minitas de cobre de buena ley (Paulino Bordones, El Bolo, septiembre 1996 en Molina 2004).
Otro colla agrega:

El trabajo de la leña y el carbón duró hasta como el año 1974. Ese año salió un decreto que prohibió la corta de leña y, a la vez, la fabricación del carbón. Incluso salió un decreto para eliminar todo el ganado caprino... (solo se peleó)... el puro asunto del ganado ya que mucha gente - tal como ahora- dependía del ganado, de las cabras, para su familia (Marcos Bordones, Pastos Largos, septiembre 1996).

La represión económica fue acompañada desde 1973 por el control militar de la cordillera, que se vio reforzado en 1978 con motivo del diferendo limítrofe austral argentino-chileno, lo que impactó negativamente en la arriería y las actividades de intercambio con el valle de Fiambala, e impidió a los collas acceder a antiguos territorios de pastoreo, localizados entre la Laguna del Negro Francisco y las Vegas de Pastos Largos, cercanos al límite internacional con Argentina.

En 1974 ocurre un desgraciado hecho presente en la memoria colla. Se trata de la muerte de las hermanas Quispe Cardoso, posiblemente provocada por efectos políticos vinculados con el golpe de Estado, a los bandos militares y a la ocupación militar de la cordillera: "Lo de las hermanas Quispe ha dado mucho que hablar, mucho comentario ha habido en eso..." (Paulino Bordones, El Bolo, septiembre 1996). En la vega La Tola, las tres hermanas aparecen muertas amarradas a una gran roca, junto a sus perros, y en el suelo el ganado caprino sacrificado. Algunos piensan que esta fue una muerte ritual, una inmolación para volver al equilibrio perdido tras el golpe militar (Farías 2005). Otros señalan como responsables a los militares: “¿Las niñas Quispe que mataron para la cordillera venían por aquí?' me preguntó. Sí le contesté..., (me dijo) yo sé verdaderamente que las mataron... porque "las niñas" estas daban facilidad a los comunistas para que se arrancaran para la Argentina, por eso las mataron (los militares)". (Paulino Bordones, El Bolo, Septiembre 1996, en Molina 2004). Por sus características y la ocasión en que ocurren esta inmolación o crimen, los hechos apuntan a la represión económica y la ocupación militar de la cordillera que impuso la naciente dictadura. Quizás este caso por falta de asesoría jurídica, temor o desconocimiento aún 
no ha sido llevado por los collas al ámbito de los derechos humanos. Hasta ahora solo ha sido un recuerdo trágico, una marca memorable, de la que se habla en voz baja.

Existen otras marcas memorables en los relatos collas, relacionadas con las migraciones y abandono del territorio de pastoreo, que han ocurrido desde la década de 1970 hasta la actualidad y que reconfiguran la realidad colla. Mientras en pueblos y ciudades vive la gran mayoría de la población que se autoadscribe colla, en el campo los pastores y pastoras, preferentemente personas adultas o de la tercera edad, van en franca disminución. En el sector Potrerillos en 1997 existían 12 pastores y en 2012 solo quedaban dos, disminución provocada por el abandono de la actividad y el fallecimiento de varios pastores (Molina y Correa 1997, Diario de campo del autor 2012). Esta disminución compromete en el futuro cercano el pastoreo, la trashumancia, la reproducción sociocultural tradicional de los collas y la capacidad para sostener la reivindicación política de los territorios. Es posible que existan otras marcas memorables contemporáneas, asociadas a la formación de comunidades indígenas a partir de 1995, a la entrega de tierras en 1998-1999, o referidas a la penetración de grandes y medianas empresas mineras que se instalan desde el año 2000 en sus antiguos territorios de pastoreo, cuyos impactos socioambientales y económicos no son del todo asimilados o percibidos aun como marcas memorables. Cualquiera sean las nuevas marcas memorables, ellas deberán ser sometidas a una descripción densa para que los hechos del pasado hagan sentido en el presente.

\section{Reflexión Final}

Las marcas memorables como relatos producto de la interrogación de la memoria constituyen una fértil fuente de conocimientos para describir la presencia colla y su compleja trayectoria en el desierto y la cordillera de Atacama. Estas marcas memorables, como descripción densa, podrán ayudar a construir la historicidad colla, dotar de contenidos a su etnicidad y aportar a una memoria colectiva en formación, por cierto polifónica y asociada a distintos hábitats geográficos y sucesos locales. Las marcas memorables advierten de los quiebres y conflictos ocurridos en la vida cotidiana, introducen en los eventos que fracturan el tiempo y evidencian los cambios históricos ocurridos en la vida social durante gran parte del siglo XX y el presente.

Las marcas memorables hablan de los impactos de la naturaleza y los conflictos sociales. Entre estos las reiteradas sequías, las pérdidas de aguas y de territorios de pastoreos, de la contaminación, disputas con hacendados, intervención de empresas mineras, procesos de asalarización, abandonos de asentamientos y migración a centros urbanos. Estos acontecimientos pueden ser relacionados en algunos casos con factores políticos, como los efectos del golpe de Estado de 1973, los conflictos internacionales de 1978, la política agraria neoliberal y el abandono del apoyo a la producción campesina. También está el reconocimiento legal de la etnia colla en 1995, la entrega de tierras en 1998 y 1999, y como corolario la penetración de grandes empresas mineras que se instalan en sus antiguos territorios de pastoreo, todos hechos que pueden transformarse en marcas memorables.

Las marcas memorables en los relatos colla devuelven al desierto de Atacama una nueva temporalidad social y cultural. El rescate de la palabra, del testimonio y del recuerdo devela episodios desconocidos, sistematiza diacronías y sincronías de acontecimientos que han estado fuera del conocimiento del Estado y de las ciencias sociales. La relevancia del estudio de las marcas memorables, como eventos significativos, nos adentra en las dinámicas de los cambios históricos que ocurren en la cotidianidad de los pueblos indígenas, aporta a los procesos de etnicidad y a la construcción de una memoria histórica que interpela al pasado y puede construir presente.

Agradecimientos: Agradezco a los evaluadores sus comentarios críticos que fueron relevantes en el mejoramiento del texto y las ideas expresadas. Igualmente, a los viejos collas, ausentes y presentes, que en largas conversaciones me entregaron sus historias memorables. 


\section{Referencias Citadas}

Bahamonde, M. 1978. Diccionario de Voces del Norte de Chile. Editorial Nacimiento, Santiago.

Bibar, J. 2001. Crónica de los Reinos de Chile. Edición de Ángel Barral Gómez. Dastin, Historia, Madrid.

Candau, J. 2006. Antropología de la Memoria. Ediciones Nueva Visión, Buenos Aires.

Castillo, G., M. Cervellino y D. Quiroz 1993. Los Collas, Fantasmas en la Cordillera. Fondo de Apoyo a la Investigación. Informes, pp. 32-35. Centro de Investigaciones Diego Barros Arana, DIBAM, Santiago.

Cervellino, M. 1993. Ritos Collas en la Región de Atacama. Revista Museos 15:4-5.

Cervellino, M. y P. Zepeda 1994. Collas: pueblo del Salar de Pedernales. Boletín del Museo Regional de Atacama 4:89-95.

Cobs, M. 2000. Entre las Nubes y el Viento: Memoria Histórica de la Vida de Don Marcelino Castro y el Asentamiento Colla de Doña Inés Chica. Tesis de Grado del Instituto de Historia, Facultad de Filosofía y Educación, Universidad Católica de Valparaíso.

Escolar, D. 2005. Apuntes sobre 'etnogénesis' y 'emergencia' huarpe: cultura, estatidad e incorporación en la frontera argentina-chilena. En Nacionalidades e Etnicidade em Fronteiras, organizado por R. Cardoso de Oliveira, S. Grant Baines y A.M. Fernandes, pp. 85-115. Editora UMB, Fundacao Universidade Brasilia, Brasilia.

Farías, R. 2005. Tres muertas inquietantes. Revista Paula 927:21-23.

Gadamer, H-G. 2001 [1973]. Verdad y Método I. Traducido por A. Agud Aparicio y R. de Agapito. Ediciones Sígueme, Salamanca.

Garrido, C. 2000. Informe Antropológico, Comunidad Colla Potrerillos. Informe Final del proyecto Conadi. Consultora INAS-Conadi Norte, Chile. Manuscrito en posesión del autor.

Gavilán, V. y A.M. Carrasco 2009. Festividades andinas y religiosidad en el Norte Chileno. Chungara Revista de Antropología Chilena 41:101-112.

Geertz, C. 1973. La Interpretación de las Culturas. Editorial Gedisa, Barcelona.

Grebe, M.E. 1981. Cosmovisión Aymara. Revista de Santiago 1:61-79.

Giddens, A. 2000. Sociología. Alianza Editorial, Madrid.

Griem, W. 2005. Historia del Clima en la Región Atacama. GeoVirtual. http://www.geovirtual.cl/Clima/Histclima01.htm (20 abril 2009).

Halbwachs, M. 2002. Fragmentos de la Memoria Colectiva. Athenea Digital $\mathrm{N}^{\mathrm{o}}$ 2, Universidad Autonoma de Barcelona. http://atheneadigital.net/article/view/52/52 (5 diciembre 2013).

Iribarren, J. 1976. Inkas, Changos y Collas. Universidad de Chile, Sede La Serena. Conferencia Magistral Inicios Año Académico.

Iribarren, J. y H. Bergholz 1973. El Camino del Inca en un sector del Norte Chico. Actas del VI Congreso de Arqueología Chilena, pp. 229-266. Universidad de Chile/Sociedad Chilena de Arqueología, Santiago.
Le Goff, J. 1982. El Orden de la Memoria. El Tiempo como Imaginario. Ediciones Paidos, Barcelona, Buenos Aires, México.

Manríquez, V. y J.L. Martínez 1995. Estudio Diagnóstico de la Población Colla de la III Región (Preinforme Final). Investigación Etnohistórica. Sur Profesionales Ltda. Manuscrito en posesión del autor.

Martínez, G. 2001. Saxra (diablo) Pachamama, música, tejido, calendario e identidad entre los Jalq'a. Estudios Atacameños 21:133-152.

Martínez, J.L. 1998. Pueblos del Chañar y El Algarrobo: Los Atacamas en el Siglo XVII. Ediciones de la Dirección de Bibliotecas y Museos, Colección Antropología, Santiago.

Molina, R. 2004. Los Collas de la cordillera de Atacama. En La Memoria Olvidada: Historia de los Pueblos Indígenas de Chile, editado por J. Bengoa, pp. 213-242. Cuadernos Bicentenario. Presidencia de la República. Santiago.

----2008. Presencia y asentamientos Collas en el desierto de Atacama. Actas del II Encuentro de Historia Comunal "Reflexionando sobre el pasado de la Frontera Norte de Chile, la Provincia de Chañaral”, pp. 63-78. Ilustre Municipalidad de Diego de Almagro.

----2010a. El despoblado de Atacama; diversidad ambiental, evidencias históricas y etnográficas de su poblamiento. Actas del XVII Congreso Nacional de Arqueología Chilena Vol. 2, pp. 1415-1428. Sociedad Chilena de Arqueología, Universidad Austral de Chile.

----2010b. Collas y Atacameños en la Puna y el Desierto de Atacama y el Valle de Fiambalá: Sus relaciones Transfronterizas. Tesis Doctoral. Universidad de Tarapacá-Universidad Católica del Norte. Arica-San Pedro de Atacama.

----2012. Los Collas: Identidad y relaciones interculturales. En Pueblos Originarios y Sociedad Nacional en Chile: La Interculturalidad en las Políticas Sociales, coordinado por J. Durston, pp. 93-113. Programa de Naciones Unidas Para el Desarrollo (PNUD), Santiago.

Molina, R. y M. Correa 1997. Estudio e Identificación de las tierras fiscales ocupadas por comunidades y personas collas en la III Región de Atacama. Comunidad Colla de Potrerillos. Informe Final. Grupo de Investigación TEPU. Manuscrito en posesión del autor.

Molina, R., N. Yáñez y D. Peña 2000. Diagnóstico territorial de las Comunidades Collas, III Región de Atacama. Grupo de Investigación TEPU-CONADI; Iquique. Manuscrito en posesión del autor.

Nora, P. 2009. Pierre Nora en Les Lieux de Mémorie. LOM Ediciones, Santiago.

Ortega, F. 2011. El trauma social como campo de estudio. En Trauma, Cultura e Historia: Reflexiones Interdisciplinarias para el Nuevo Milenio, editado por F. Ortega, pp. 17-59. Universidad Nacional de Colombia, Bogotá.

Ponce, R. 1998. ¡Añapiando...Añapiando! Antecedentes Históricos del Pueblo Colla de la Región de Atacama. Talleres Gráficos Lo Bilbao. Copiapó. 
Ricoeur, P. 2003. La memoria, la historia y el olvido. Editorial Trotta, Madrid.

Rosa, A., G. Bellelli y D. Backhurst 2000. Representaciones del pasado, cultura personal e identidad nacional. En Memoria Colectiva e Identidad Nacional, editado por A. Rosa, G. Bellelli y D. Backhurst, pp. 41-90. Biblioteca Nueva. Madrid.

Rojas, C. 1976. El Mundo Mágico de los Collas. Memoria para optar al Título de Profesor de Estado en Castellano. Universidad de Chile, La Serena.

Sitton, T., G. Mehaffy y L. Davis Jr. 2005. Historia Oral. Una Guía para Profesores (y otras personas). Fondo de Cultura Económica, México.

Schutz, A. 1974. El Problema de la Realidad Social. Amorrortu Editores, Buenos Aires.
Van den Berg, H. 1989. La Tierra no da Así no Más: los Ritos Agrícolas en la Religión de los Aymara-Cristianos de los Andes. CEDLA, Amsterdam.

Van Kessel, J. 1992. La organización tempo-espacial del trabajo entre los aymarás de Tarapacá: la perspectiva mitológica. Etnicidad, economía y simbolismo en los Andes. Actas del II Congreso Internacional de Etnohistoria. pp. 267-298. Ediciones Hisbol, La Paz.

Vicuña, M. 1995. La Imagen del Desierto de Atacama (XVI$X I X)$. Colección Humanidades. Ensayo. Editorial Universidad de Santiago, Santiago.

Wendy, R. 2000. Historia oral, trauma y tabú. Historia, Antropología y Fuentes Orales 23:121-133. 